\title{
Shaping wicked problem solvers: innovating educational programs through design thinking
}

\author{
Christian Johansson $^{1}$, Santosh Jagtap ${ }^{1}$, Marco Bertoni ${ }^{1}$, Alessandro Bertoni ${ }^{1}$, Johan \\ Wall ${ }^{1}$ \\ ${ }^{1}$ Blekinge Institute of Technology \\ cmj@bth.se \\ santosh.jagtap@bth.se \\ marco.bertoni@bth.se \\ alessandro.bertoni@bth.se \\ johan.wall@bth.se
}

\begin{abstract}
Societies across the globe are facing many unprecedented challenges; climate change, pandemics, and resource depletion, just to name a few. These societal challenges, the 2030 Sustainable Development Agenda, and companies' demands about knowledge and skills required from future employees have put pressure on academia to develop suitable education programmes in many disciplines, including product development and mechanical engineering. In this position paper, we present our work undertaken in phase- 1 of the development of a new MSc programme in the field of product development and mechanical engineering at Blekinge Institute of Technology, aimed at addressing changing societal needs and demands of the future industry. We employ a generic design thinking approach, starting from key stakeholder needs with iterative execution of needfinding, benchmarking, and ideation. In these steps, we use several data collection and generation methods such as interviews, surveys, and workshops. The main outcome of phase- 1 is the overall programme structure, consisting of three main focus streams - the engineering design core, three academic specializations (Product-Service Systems Design, Data-Driven Design, and SimulationDriven Design), and the practical application profiling. Based on our experience of developing the overall programme structure, we offer recommendations for developing new programmes in this area.
\end{abstract}

Keywords: education programme, product development, mechanical engineering, wicked problems, design thinking, t-shaped engineers, data-driven design, simulation-driven design, product-/service systems

\section{Introduction}

Climate change, resource depletion, pandemic outbreaks, species extinction, chemical pollution, and social problems (e.g., poverty) in many parts of the world collectively represent one vast problem for human civilization: un-sustainability. The 2030 Sustainable Development 
Agenda (United Nations, 2015) stresses how these unprecedented challenges are rooted in systemic flaws in the basic operation of our society and how the foundation for long-term prosperity is systematically degrading on the global scale as long as these root causes remain. From a technical standpoint, these challenges liken wicked problems (Rittel, H. W. J., \& Webber, M. M., 1973): they cannot be solved in a traditional linear fashion, because the problem evolves as new possible solutions are considered and implemented. Their high degree of complexity and ambiguity mean that there is not necessarily a single right or wrong solution, but only solutions that are 'better', 'worse' or 'good enough'. The overwhelming technical and social complexity of wicked problems calls for new type of individuals that are able to combine disciplinary expertise in their domains and broad cross-cutting knowledge to other fields. The concept of T-shaped engineers (Oskam, I., 2009) captures this need of combining expertise and transcending boundaries in engineering education.

The need for providing solutions to the above challenges is pushing the manufacturing industry to engage even more in business-to-business collaborations and to partner with sectors of society traditionally far from the core business of the company. In turn, this emphasise the need to recruit and develop multi-skilled staff (who can transcend traditional disciplines) and to adopt a life-cycle thinking - moving towards circular economy operation where reuse, repair, reconditioning and refurbishment become part of a manufacturer's business. One clear manifestation of these phenomena is the emerging servitization trend where exploration of product-service systems (PSS) (Mont, O., 2002) approaches (e.g., functional offerings, total site ownership, through-life support, power-by-the-hour) is becoming increasingly important, as it covers the entire process from the need to its satisfaction.

PSS and its inherent sustainability potential are at the core of our research at the Department of Mechanical Engineering, Blekinge Institute of Technology. Despite a growing interest in sustainable PSS innovation in the industry, it is not yet fully understood how this shifting perception will affect the development processes for the physical artefacts and technologies, or how companies should successfully operate and cooperate in the increasingly sustainabilitydriven global market. Here, methods and tools to support circularity in thinking and acting must be experienced as, and function as, a natural part of everyday work.

The changing needs of societies around the world and the industry's demands for future employees motivate the development of suitable education programmes in the area of product development. To meet these societal needs and industrial demands, we have started to develop an MSc programme in Mechanical Engineering at Blekinge Institute of Technology. In this position paper, we present the work carried out in development phase 1 . This work is based on data, findings and insights gathered from activities such as workshops, interviews and surveys with several professionals working in companies, as well as collegial discussions and workshops with researchers and teachers at our Department of Mechanical Engineering. This position paper will be useful to those universities that want to renew their existing education programmes, as well as for those that want to develop new programmes in product development and mechanical engineering. Following this introduction, the rest of the paper is structured as follows. Section 2 presents the approach that we have used. Section 3 outlines the findings from data collection about future expectations of mechanical engineers, followed by section 4 , where we present the overall structure of the MSc programme based on these insights. Finally, section 5 discusses the overall programme structure, while offering recommendations for the development of education programmes in the field of product development and mechanical engineering. 


\section{Programme development methodology}

The Design Thinking (DT) approach (Brown, T., \& Katz, B., 2019) (Figure 1) has been used as main reference for the development of the MSc programme. Beyond being a teachinglearning approach in education, DT is also well-positioned as a curriculum design methodology (Lor, 2017), especially when there is a need to shift approach from teaching content only towards practical problem solving with a balance of theory critical thinking, hands-on design in projects providing active learning. Further, the intrinsic focus on key stakeholder empathy, user-orientation, integrative thinking, and prototyping makes DT a good approach for ensuring that students, industry is listened to upfront and throughout, as well as that experimentation is at the core. The programme development is based on close relationships with our main stakeholders - the companies and students. We have employed methods and tools from human-centred and creative design methodologies to develop a novel programme with curricula and courses that are based on stakeholder needs.

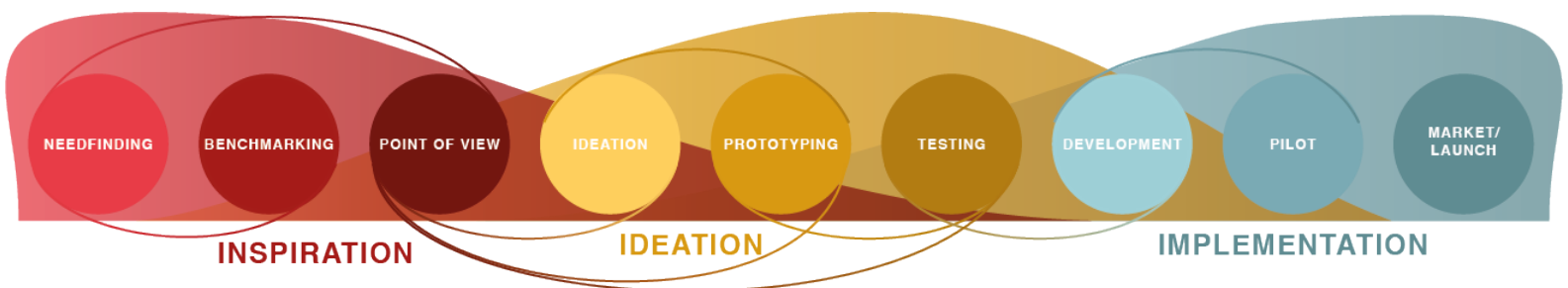

Figure 1. The Design Thinking approach adopted for the development of the MSc programme.

Whilst Figure 1 presents all steps of the DT approach, in this paper, we present the work accomplished in phase-1 of the programme development, consisting of the first four steps.

(1) Needfinding: here the industry's expectations and needs for modern mechanical engineering skills were solicited. Similarly, students' wishes and needs from education are gathered. As we are looking to future changes and evolution in relevant domains with changing requirements and expectations, we have also focused efforts on trendwatching activities where organizations attempt to forecast how the education landscape will shift based on societal changes and technological developments.

(2) Benchmarking: includes learning from the well-recognised universities, both nationally and internationally. We have undertaken research and visited leading players in the field of product development and mechanical engineering, such as Stanford University, Carnegie Mellon University, TU Delft, and Singapore University of Technology and Design. Additionally, we have participated in pedagogic (e.g., CDIO) forums and conferences.

(3) Point of View: based on findings from steps 1 and 2, we have iteratively analysed the findings, to sketch points of departure in terms of overall constituent structures and aspects that needs to be integrated, ensuring a trade-off of flexibility and coherent identity in the cohort.

(4) Ideation: is the creative development of the solution components that will be brought together in the new program. This has been undertaken in a creative and continuously iterative setting with several stakeholders.

The above steps have been undertaken in an iterative and concurrent approach, as highlighted in the figure, allowing to develop the programme structure gradually. In these steps, we have employed several methods such as interviews, surveys, and workshops.

As we launched the education development initiative, we conducted a series of workshops both with teacher colleagues in the education programme as well as with industry practitioners that are affiliated with the development initiative. Planning the workshop series with the Move workshop method (Carleton, T., Larsson, A. \& Bill, S., 2011) with the Now-Wow-How 
approach, we encouraged the participants to take a point of departure in the current realities (the Now-step) and challenges of education and practice, essentially looking both to aspects where participants see aspects as "broken" or bland, specifically with a view of having a distinctly profiled education offering. The next step (Wow) of the method focuses on visualizing the ideal situation without limitations; who is our ideal student/graduate, ideal topics to cover, ideal courses and programs. From these, we drew up areas and actions (in the Howstep) that should be investigated further as a foundation for the development, as well as lowhanging fruits that might be possible to address short-term.

Semi-structured interviews were held with five manufacturing companies, all SMEs located in south-east Sweden. Respondents, managers and practitioners in product development, were selected primarily based on previous interest for cooperation in research or education. The topic centred on the company's product development practices, use of support tools and methods, as well as their rationale for these. Also, their outlook on their futures in their industry and what they see will be required to remain competitive was probed. Finally, their expectations, requirements and wishes from future employees, i.e. the engineering students of tomorrow were discussed. Further inputs to the definition of the program requirements and content have been obtained in regular multi-day physical workshops involving large-scale manufacturers collaborating in ongoing research projects at the authors' institution.

To triangulate these findings, an online survey featuring multiple-choice questions was shared with selected engineering practitioners to explore future requirements for skills and capabilities that might be relevant for a mechanical engineer in 5 to 10 years. A total of 28 individual answers were collected, of which eleven from practitioners in the aerospace, automotive, naval and construction machinery sectors, seven from consultants, six from medium-small engineering companies, and one each from a recruitment company, a company in the telecommunication sector, and a public agency. Finally, one wished to not declare their employment.

Students' participation is continuously sought via forums, such as programme committees, and meetings with programme management. A major source of information is also represented by the student design reflections at the end of each course, which are regularly analysed to identify relevant features for the evolution of the engineering curriculum.

\section{Expectations on the future mechanical engineer}

During our research with companies, we discussed topics relating to expectations from future employees in the field of product development and mechanical engineering. Noticeably, and far from surprising, the applicants are expected to understand basic topics of product development and engineering, fundamental principles of mechanics and machine elements, and to possess a solid understanding of the product development process in its entirety. Innovation engineering methods are seen as a competitive advantage for many companies and they see students and new employees as the ones who will bring some fresh ideas to their organizations. As companies move closer to the digitization and digital product development, they also see a need to automate and streamline design and analysis activities, for instance through the use of apps and macros in the engineering software packages. Many of the companies also product connectedness and the Internet of Things - which is, being proficient in programming and able to collect and analyse sensor data - to be key abilities for future engineers. Beyond this, they rely on their new hires to bring them up to speed with new technologies such as 3D printing, 3D scanning, Virtual Reality and more, which is something they often struggle to do with the current generation of employees. 
In addition to these descriptive study findings, the survey highlighted that the three main skills lacking today in the respondents' engineering group to be Systems Engineering, Communication (highlighted by 13 respondents), and Innovation processes (highlighted by 10 respondents). With regards to what companies foresee to become critical skills for mechanical engineers in 5 to 10 years, 16 respondents highlighted "Creativity", 15 respondents highlighted "Radical innovation thinking", 14 respondents highlighted "Sustainability assessment" and "Solid mechanics". Figure 2 provides and overview of the main trends and capabilities which have been found to characterize future engineering education by the company partners.

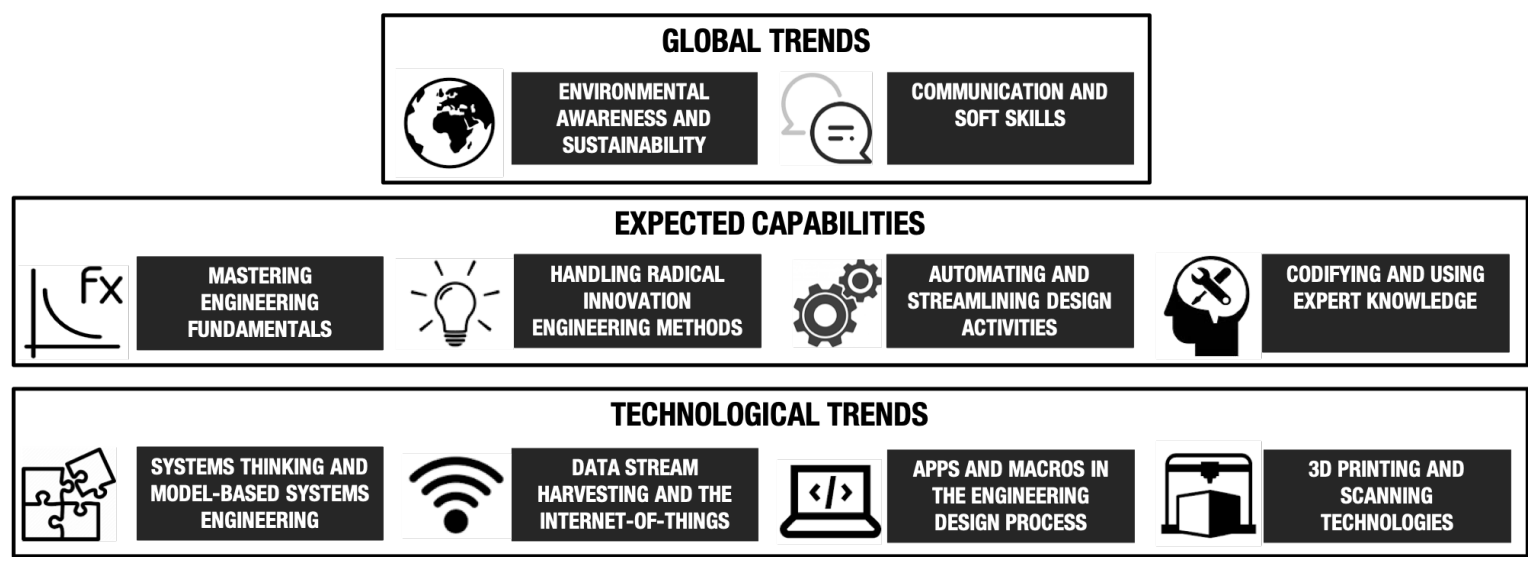

Figure 2. Main findings from trends and capabilities for future engineers as resulting from the needfinding study at the company partners.

Reviewing some trends that are identified by e.g. World Economic Forum, Boston Consulting Group (see Figure 3), and UNESCO (Anon. 2015a; Jahanian, F. 2020; Anon. 2015b) indicate that the higher education landscape will see an imminent shift away from $20^{\text {th }}$ century education logics, into responding to evolving needs stemming from the shift towards the knowledge-based economy, with increased fluidity and a shifting employability landscape. With changes coming from advent of disruption of new advanced technologies, such as automation, there is a need to facilitate re-skilling and up-skilling as well as laying a foundation for new graduates for a skillsand knowledge foundation that may then be updated and transformed - hence, we see several emphasizing lifelong learning - in collaborative private-public partnerships. Also, we find demand on soft skills (e.g., teamwork, decision-making, communication, collaboration - in reallife project contexts), critical thinking, problem solving, creativity, and the T-shaped approach (combining vertical expertise with horizontal knowledge). Personalized and technologyenhanced learning; such as blended learning, combinations of MOOC (Massive Open Online Course) materials with traditional face-to-face modes, as well as flexible curricula, with students being consumers and combining offerings from several providers, is projected.

\begin{tabular}{|c|c|c|}
\hline $\begin{array}{l}\text { FOUNDATIONAL LITERACIES } \\
\text { How students apply core skills to everyday tasks }\end{array}$ & $\begin{array}{c}\text { COMPETENCIES } \\
\text { How students approach complex challenges }\end{array}$ & $\begin{array}{c}\text { CHARACTER QUALITIES } \\
\text { How students approach their changing environment }\end{array}$ \\
\hline $\begin{array}{l}\text { 1. Literacy } \\
\text { 2. Numeracy } \\
\text { 3. Scientific literacy } \\
\text { 4. ICT literacy } \\
\text { 5. Financial literacy } \\
\text { 6. Cultural and civic literacy }\end{array}$ & $\begin{array}{l}\text { 7. Critical thinking/problem solving } \\
\text { 8. Creativity } \\
\text { 9. Communication } \\
\text { 10. Collaboration }\end{array}$ & $\begin{array}{l}\text { 11. Curiosity } \\
\text { 12. Initiative } \\
\text { 13. Persistence/grit } \\
\text { 14. Adaptability } \\
\text { 15. Leadership } \\
\text { 16. Social and cultural awareness }\end{array}$ \\
\hline
\end{tabular}

Figure 3. Skills for 21 st century, combining focus on foundational literacies, competencies, and charter qualities (source: Boston Consulting Group (Anon. 2015a)). 
Feedback from present students on the program indicated that they are often tuned into the trends that are going on around them and ask for new courses and updates to the curriculum in line with, for instance the advent of internet of things and other technological trends.

\section{Programme structure}

The current Mechanical Engineering MSc programme is one of the seven five-year MSc programs at Blekinge Institute of Technology. Presently, the programme admits up to 45 new students every year. The first three years follow a traditional common curriculum for all students, which includes mathematics, physics, and classic mechanical engineering courses, such as Solid Mechanics, Machine Elements, Dynamics, Thermodynamics, Material Science, and Computer-Aided Design. Knowledge and skills are put to use in several project courses where students work with problem-based learning in real-life contexts. Thereafter, for years four and five, the students choose one out of two specializations, namely, 'Innovative- and Sustainable Product Development' or 'Applied Mechanics'. In the 'Innovative and Sustainable Product Development' specialisation, the focus is on innovation engineering, value-driven design, sustainable product development, and engineering design methods to educate creative problem solvers and developers of new products and services. In the specialisation 'Applied Mechanics', the focus is on comprehensive and advanced models, calculations, experiments and simulations of product properties to verify and optimize products for their use.

The new MSc programme aims to educate and prepare engineering students for digital product development to be able to collaboratively engineer future innovations in an environment that is permeated by modelling, simulation and data-driven development of complex product-service system solutions, and are thus attractive and employable by both the companies that have participated in our research, but also other companies that want to develop in this direction.

\subsection{Traits of the future mechanical engineer}

Increasingly, few problems are confined to a single functional domain, and these problems are rarely laid out in perfect definitions to be solved. Problems are ill-defined and wicked (Rittel, H. W. J., \& Webber, M. M., 1973) in character, meaning that engineers need to be trained in finding and defining their problems and that they can be complex, ambiguous and contradictory to define and thus solve optimally. As already Cross (1982) alluded to, new designers and engineers must be taught to be wicked problem solvers, meaning that there is no definite formulation, but very tightly aligned with a chosen strategy for solution, based on several layers and alternatives by which to solve and continuously improve on solutions that are not in essence right or wrong, but better or worse, where iterations lead to better solutions. These problems and solutions more often reside at the intersections of different traditional disciplines, where the traditional boundaries are becoming more porous. Mechanical engineers, as other professions, need training in working together with people that know other domains to bring forward the best of several worlds in innovation.

Therefore, the importance of being a 'T-shaped' engineer (Oskam, I., 2009), working in crossfunctional $\mathrm{T}$-shaped engineering teams with other professions, is increasing due to the everincreased complexity when developing the products and also to understanding the context (see Figure 3). Teams are composed of the necessary competences to extract the maximum potential from the individuals in their domain, and also provide opportunities for innovation at the intersection. Additionally, due to the ever-increased need of new products/services as a result of shorter product lifecycles (Barszak, G., et al., 2009), cross-functional work has become an effective way when developing new solutions (Cooper, P., 2005). In this context, the T-shaped 
engineer needs the knowledge to understand the basics in relating disciplines, such as data science, internet of things, computer-aided engineering, service engineering, and innovation engineering, etc. However, cross-functional work also involves collaboration with other technical- and non-technical disciplines, such as production, automation, industrial economics. This requires the T-shaped engineer to possess abilities to simultaneously, in collaboration with other experts, analyse ongoing product development in the light of environmental- and business requirements as well as the mechanical challenges.

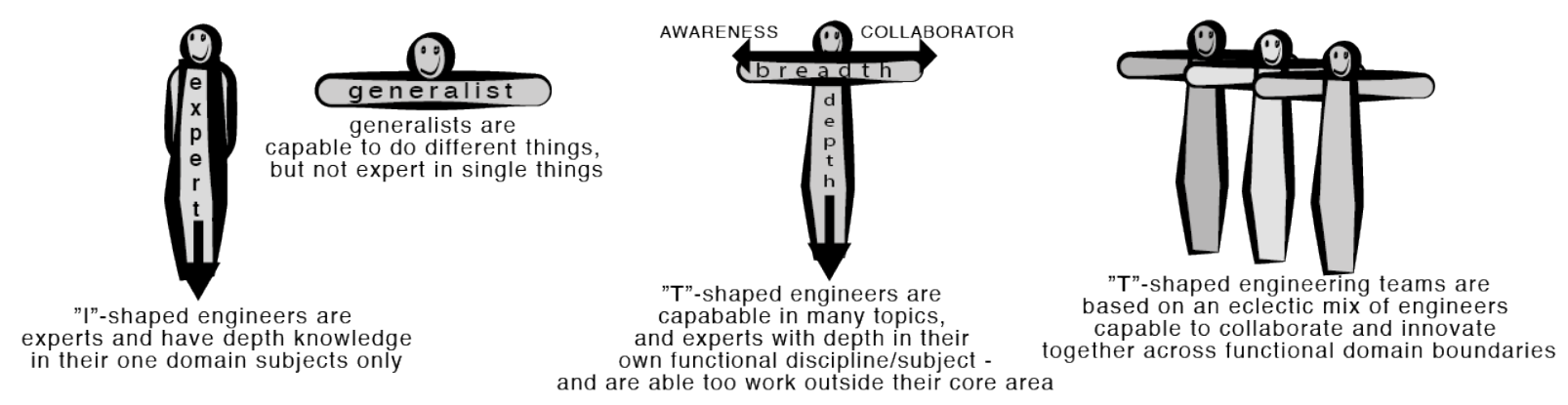

Figure 4. T-shaped engineers forming T-shaped engineering teams (adopted from Oskam, 2009).

Engineering graduates are often acquainted with the scientific method and the engineering design process. However, they are most comfortable — and sometimes quite good at focusing on the technical feasibility of a solution. Yet, the community of engineering educators worldwide agrees on the need to foster an entrepreneurial mindset in engineering graduates. The latter shall not only design new products and services simply based on technical and functional concepts taught, but rather with a 'value proposition' and 'user needs' in mind. Many potential innovations have been technically feasible but were not as viable and made little business sense.

As the design process moves from discovery to evaluation and then to exploitation, engineers continually iterate through the engineering design process with the ultimate goal to answer questions including 'Do they want this?', 'Can we do this?', and 'Should we do this?' - which is to validate, technological feasibility, customer desirability, and business viability. This entrepreneurial, value-driven attitude must become a major feature in future engineering education. Differently from traditional problem-based learning, these value-driven experiences shall be conceived to serve a broader purpose than just designing a solution; they shall contribute to added value for society. The spirit of value-driven design (VDD) experiences (Bertoni, M., Eres, H., \& Scanlan, J., 2014) is to open up the solution space for consideration by designers, systems engineers, programme managers, and customers by promoting quick what-if analyses that use a value function as metrics to judge the goodness of a design. A crucial activity for students is then to determine the connections between the technical attributes of the system they are designing to the overall 'value' function capturing desirability and viability aspects. This activity requires cross-disciplinarity and benefit from both depth and breadth in education.

\subsection{Overall structure of the new program}

The most important result from data collection is the definition of the overall program structure. The current structure of the master years (years 4 and 5) with distinctly different tracks should be replaced with a common core engineering design grounding for clearer identity and then offering up added freedom to specialize deeper in an area of interest and also to explore a specific contextual application in practice via project works (see Figure 5). The details are presented below. 


\begin{tabular}{|c|c|c|c|}
\hline YRS 1--3 & YR4/SPRING & YR5/FALL & YR5/SPRING \\
\hline $\begin{array}{l}\text { [FOUNDATIONS] } \\
\text { MECHANICAL } \\
\text { ENGINEERING } \\
\text { FOUNDATIONS }\end{array}$ & $\begin{array}{l}\text { [SPECIALIZATIONS] } \\
\text { SPECIALIZATION TRACKS }\end{array}$ & $\begin{array}{l}\text { THEMES: } \\
\text { Data-Driven Design } \\
\text { Simulation-Driven Design } \\
\text { Product-Service Systems }\end{array}$ & [SUMMATIVE EXPERIENCES] \\
\hline $\begin{array}{l}\text { (Math, Physics, } \\
\text { Solid Mechanics, } \\
\text { Machine Elements, } \\
\text { Dynamics, }\end{array}$ & $\begin{array}{l}\text { [DISCIPLINARY COURSES] } \\
\text { ENGINEERING DESIGN SPINE }\end{array}$ & $\begin{array}{l}\text { THEMES (e.g.): } \\
\text { Design//nnovation methods } \\
\text { Modelling, Simulation, Prototyping } \\
\text { Value Innovation }\end{array}$ & $\begin{array}{c}\text { MASTER } \\
\text { THESIS }\end{array}$ \\
\hline $\begin{array}{l}\text { Material Science, } \\
\text { Thermodynamics, } \\
\text { Computer-Aided Design, } \\
\text { Prototyping, } \\
\text { Practicum, etc.) }\end{array}$ & $\begin{array}{l}\text { [SUMMATIVE EXPERIENCES] } \\
\text { PRACTICUM: TEAM/INDIVIDUAL PROJECTS }\end{array}$ & $\begin{array}{l}\text { THEMES (e.g.): } \\
\text { Frugal Innovation } \\
\text { Design for Wellbeing } \\
\text { Performance Engineering }\end{array}$ & \\
\hline
\end{tabular}

Figure 5. The overall structure of the new MSc programme.

\subsubsection{Engineering design core}

Lending inspiration from Stevens Institute of Technology with their design spine (Anon. 2019), we put the product development engineer in focus and the backbone of the new programme is an engineering design core curriculum - as opposed to having it as one of many specializations. Students share a core stream of engineering design content that provides them with common knowledge and skills, making them all valuable team members in product development teams. The contents here include engineering design methods (e.g., design thinking, systems engineering), value innovation, modelling (model thinking), simulation, prototyping and Design-Build-Test iterations, experiments and measurements, product service system design, and programming. This builds a common identity for all students, allowing them to take roles in the same product development teams.

\subsubsection{Academic specialization}

The second stream focuses on specialization, which is identified based on results from needfinding and research results. These areas of specialization are Product-Service System Design, Data-Driven Design and Simulation-Driven Design.

Product-Service Systems Design - Integrated solutions, variously discussed using terms such as 'total care product', 'functional products', 'integrated products and services', and 'productservice systems' (PSS), contribute towards satisfying end users' needs, with efficient use of assets and resources (Jagtap, S., \& Johnson, A., 2011). The focus is on developing a 'needsatisfying system', rather than on specific components. The drivers and benefits in the context of developed countries include, among others, creating unique selling propositions and alleviating environmental impact (Mont, O., 2004). Mechanical engineers play an important role in designing integrated solutions, requiring appropriate design methods, tools, and skills. Students will learn underlying theory, design guidelines, methods, and tools, to design integrated products and services not just for developed countries but also for Base of the Pyramid (BOP) markets in developing countries, where the characteristics of designing integrated, frugal solutions differ from those in developed countries (Jagtap, S., 2018). The design of frugal innovations for BOP markets is largely driven by the necessity of satisfying unmet or under-served needs of marginalized people (Jagtap, S., et al., 2013), thus contributing to global sustainable development.

Data-Driven Design - The need to capture, analyse and effectively visualize data in engineering design, has been on researchers' and industrial practitioners' agenda for several decades. The term Data-Driven Design (DDD) refers to research merging competences of data science and mechanical engineering. Recent breakthroughs in development and accessibility of cyber-physical systems and internet of things have created "unmatched opportunities for advancing theory, methods, tools, and practice of DDD for products, systems, and services" (Kim, H., et al., 2017, p.1). Industries investigate the use of data mining and machine learning to better identify customer needs, to define design parameters for product improvement and to 
assess the value of alternative design concepts early (see Bertoni, A., \& Larsson, T., 2017). Despite the potential of DDD, its application is hampered by a lack of individual skills that bridge both mechanical engineering/computer science chasm. There is a comprehensibility barrier for mechanical engineers to understand and apply data-science algorithms in product development (as highlighted by Freitas, A. A., 2014). Historically, mechanical engineering and computer science education have been perceived as separate, which does not reflect reality anymore, with consideration of the emerging needs in industrial practice and applied research (Bertoni, A., 2018).

The DDD track will give students cross-disciplinary knowledge to deal with product development challenges while understanding the potential of data science applications. Students will be able to apply machine learning and data mining algorithms to reduce uncertainty in decision making and improve product development efficiency.

Simulation-Driven Design - Effective and efficient product development is crucial to business success and simulation has proven to support this in many sectors. Simulation-driven-design (SDD) is an approach that can support dialogues with customers (rather than just verify decided solutions), stimulate the creation of new concepts, and guide more optimised designs, especially in early stages of development and thus "front-load" the development (Wall, J., 2007).

For industry to harvest the full potential of SDD, they need analysts that have in-depth knowledge of engineering design together with an understanding of tools and methods to leverage simulation in exploration and search of a design space. Hence, analysts that cannot only build and execute a model in a given setting but also, within the bounds of its validity, experiment to assess how decisions affect the outcome and possibly also optimize a design to achieve the best possible outcome in a given resource frame. The SDD-track will give students specialized knowledge in modelling, simulation, design automation, and optimisation. The importance of validation is also emphasized, and students are introduced to physical experimentation and data collection and its role in the digital workflow.

A cornerstone is a movement towards a system view in design and the ability to predict and assess attributes in scenario creation of life-cycle commitments. As a consequence, applications will widen the scope of what traditionally constitutes modelling and simulation in a product development context, going beyond assessing only the performance space to also include the resource space over the complete value life. This fosters an organization-wide deployment of modelling and simulation, making the technology more readily applicable across disciplines and domains. This supports better and earlier decisions, possibly reducing lead times and costs while increasing the level of knowledge in the organization related to the products, services and processes that are modelled and simulated.

A mechanism to achieve a versatile set of specializations is the so-called 'course baskets', where students are a recommended sequence of courses that can build a chosen specialization. Adjacent specializations can share some courses, and with a choice of specific courses in other national or international institutions students can attain unique profiles with few changes.

\subsubsection{Practical application profiling (application domains/areas)}

In the third stream in the programme, we have included the summative application of both core and specialized knowledge and skills from the other two streams in projects that are crossfunctional and thematically defined. Examples of thematic areas can be applied health technology, wellbeing technologies, frugal/bottom of the pyramid innovation, innovative startups, and performance mechanics engineering. An important factor is that students can choose to come back to the same thematic area again over several years of projects and thus build on development from one project to the next and thereby specialize in that area. This also offers 
the possibility for students from different years to collaborate and also sub-contract aspects of projects between them. An important gain from this track, besides the summative experience, is also that the students gets to train their soft skills, such as teamwork and collaboration, project management, and communication.

In the final-year capstone project, we see the benefit to exposing students to the reality of global product development by striving to forge relationships with present and new partner universities as well as international capstone exchanges so students will do at least one global design project before graduating. Today we have one such project with Stanford University's Design Division ME310 course (see Johansson, C. et al. 2016 for example of project) and the aim is to expand to more projects to include all students.

The programme design and the application of the CDIO (Conceive-Design-ImplementOperate) framework of syllabus and principles offer a strong opportunity for a good learning climate for engineering design and innovation education. The engineering design core covers essential concepts which provide a common grounding and identity for all students, thus building a strong foundation for the T-shaped people and their T-shaped engineering teams. Students with diverse specializations from the program - as well as students from other programs or institutions - can join up in challenges, where they gather on a specific thematic topic and solve wicked problems together. Each student will utilize their core deep disciplinary skills while being able to collaboratively build from other student's contribution as they will be trained in crossing boundaries, tapping into the expertise of other students. Students are challenged to build soft skills and character qualities, as well as improving the skills in terms of competencies.

With specialization, we offer focus and sequence where in-depth specialization and progression within the field of interest can be achieved. One of the chief impediments to the learning process is motivation (Csikszentmihalyi, 1990). By incorporating a project application stream relying on project-based learning (with internal and external partners), each involving unique challenges and opportunities, the curriculum addresses core strategies to increase students' motivation. An ample mix of specialization skills and knowledge from the different specialization tracks, or even other programs, in an advanced application setting, with the culmination of a high-quality master thesis, aims to transform the students' perspective on knowledge from dualistic absolutists to a more contextually bound one. Facilitating reflection about the learning experience, expectations and outcomes offers a higher-order analysis where designers move away from yes/no, right/wrong answers towards finding stronger arguments and rationale for their beliefs and design concepts being better or worse, with clear rationale, and with iterations moving their design concepts from worse towards better.

\section{Discussion and conclusions}

In this position paper, we presented our work undertaken in phase-1 of the development of a new MSc programme to meet the changing societal needs and demands of industries. The design thinking approach provided a useful basis to develop the overall programme structure, consisting of three main focus streams — the engineering design core, three academic specializations (Product-Service Systems Design, Data-Driven Design, and Simulation-Driven Design), and the practical application profiling. The use of a broad range of methods such as interviews, surveys, workshops with relevant stakeholders (e.g. practitioners from companies, students, researchers, teachers, etc.) supported the activities in various steps of the design thinking approach. Although we are still in the midst of development, different sources point towards some convergence on both soft and hard aspects that are relevant skills and mindsets for future product developing mechanical engineers. Phase- 2 of the program development is 
currently ongoing, which, for example, involves detailing the overall programme structure, deciding various courses, and planning the course content. It is hoped that this work will help and inspire other universities and academics interested in renewing their existing programmes or in developing new programmes in mechanical engineering.

The program contributes to several Sustainable Development Goals, with a strong focus on goals number $3,7,8,9$ and 12 . With regards to goal number 3 , the program emphasise active work within the topic of 'design for wellbeing' as a theme in the practicum, guiding students in the application of their theoretical knowledge to realise of solutions that support higher level of wellbeing, and that encourage people to adopt healthier lifestyles. The projects in the practicum further address the transition to clean energy and a sustainable transportation system, addressing goal number 7. Overall, the programme structure and content are inspired by the will to support manufacturing companies to achieve higher levels of economic productivity through diversification, technological upgrading and innovation. By promoting the use of simulationdesign practices to conceive and assess ideas and concepts in design, students will be able to early on simulate and assess the value of a solution not only from a functional and economical viewpoint, but also looking at societal and environmental aspects, which are traditionally more difficult to grasp and include as design target for new products and services. Improved early simulation skills will contribute to growth the sustainability literacy of the students, leveraging goal number 8, 9 and 13 Eventually, the different tracks promote more responsible production by providing students with methods and tools to and forecast what life cycle benefit and drawbacks are embedded in the decision of bringing a design concept to life, hence targeting goal number 12.

Design thinking, with inherent emphasis on needfinding and iterative ideation, is a useful approach by which to develop new programs, as we bridge the perspectives of stakeholders. When analysing some of the data we can reflect that companies have a good and balanced view about their immediate challenges. Furthermore, they appreciate that they must have innovative capabilities to also think long-term, while keeping up with the buzzwords and trends. However, in detail, we found that it is more difficult to foresee changes, as is normal when asking customers in any type of design process. Hence, there is a need for change agents educating companies about emerging trends and to provide teasers via students working in collaboration, which ultimately are going to be the change agents as newly hired employees with new tools and perspectives. Therefore, it is important to continuously evolve the education offering iteratively and maintain a modern curriculum.

\section{Acknowledgment}

This work has been supported by funding from the Swedish Knowledge Foundation, within AVANS 18.

\section{References}

Anon. (2015a). New Vision for Education: Unlocking the Potential of Technology. World Economic Forum: Industry Agenda.

Anon. (2015b). Education 2030 Incheon Declaration and Framework for Action: Towards inclusive and equitable quality education and lifelong learning for all. UNESCO Declaration Report.

Anon. (2019). Engineering Core Curriculum. URL:

https://www.stevens.edu/academics/undergraduate-studies/engineering-design-spine, accessed: 2020-05-28.

Barczak, G., Griffin, A., \& Kahn, K. B. (2009). Perspective: trends and drivers of success in NPD practices: results of the 2003 PDMA best practices study. Journal of Product Innovation Management, vol. 26, no. 1, pp. 3-23. 
Bertoni, A., (2018). Role and Challenges of Data-Driven Design in the Product Innovation Process. In 16th IFAC Symposium on Information Control Problems in Manufacturing-INCOM 18.

Bertoni, A., \& Larsson, T. (2017). Data Mining in Product Service Systems Design: Literature Review and Research Questions. Procedia CIRP, vol. 64, pp. 306-311.

Bertoni M, Eres H., \& Scanlan J. (2014). Co-creation in complex supply chains: the benefit of a Value Driven Design approach. In: D. Schaefer: Product Development in the SocioSpere: Game changing paradigms for 21 st century breakthrough product development and innovation, Springer.

Brown, T., \& Katz, B. (2019). Change by design: how design thinking transforms organizations and inspires innovation. (Revised and updated edition.) New York: HarperBusiness, an imprint of HarperCollinsPublishers.

Carleton, T., Larsson, A., \& Bill, S. (2011). MOVE Beyond Great Ideas: Workshop facilitation handbook. Institute for Management of Innovation and Technology.

Cooper, P. (2005). A study of innovators' experience of new product innovation in organisations. R\&D Management, vol. 35 no. 5, pp. 525-533.

Cross, N. (1982). Design as a discipline: Designerly ways of knowing. Design Studies, vol. 3, no. 4, pp. 221-227.

Csikszentmihalyi, M., (1990). Literacy and Intrinsic Motivation. Daedalus, 119(2), pp. 115140.

Freitas, A.A. (2014). Comprehensible classification models: a position paper. ACM SIGKDD explorations newsletter, vol. 15, no. 1, pp. 1-10.

Jagtap, S. (2019). Design and poverty: a review of contexts, roles of poor people, and methods. Research in Engineering Design, vol. 30, pp.41-62. doi: 10.1007/s00163018-0294-7.

Jagtap, S., \& Johnson, A. (2011). In-service information required by engineering designers. Research in Engineering Design, vol. 22, no. 4, pp. 207-221. doi.org/10.1007/s00163011-0107-8

Jagtap, S., Larsson, A., \& Kandachar, P. (2013). Design and development of products and services at the Base of the Pyramid: a review of issues and solutions. International Journal of Sustainable Society, vol. 5, no. 3, pp. 207-231. doi/10.1504/IJSSOC.2013.05471

Jahanian, F. (2020). How higher education can adapt to the future of work. World Economic Forum Annual Meeting article. URL: https://www.weforum.org/agenda/2020/01/howcan-higher-education-adapt-to-a-constantly-evolving-future-of-work/, accessed: 202005-27.

Johansson, C., Elfsberg, J., Larsson, T.C., Frank, M., Leifer, L.J., Nilsson, N. \& Söderberg, V. (2016). Urban Mining as a Case for PSS. Procedia CIRP 47, pp. 460-465.

Kim, H., Liu, Y., Wang, Y., \& Wang, C., (2016). Special issue: Data-driven design (d3). Journal of Mechanical Design, vol. 138, no. 12, p. 128002. doi.org/10.1115/1.4035002

Lor, R. (2017). Design Thinking in Education: A Critical Review of Literature. Proceedings of the Asian Conference on Education \& Psychology. Bangkok, Thailand

Mont, O. (2004). Institutionalisation of sustainable consumption patterns based on shared use. Ecological economics, vol. 50, no. 1-2, pp. 135-153.

Oskam, I. F. (2009). T-shaped engineers for interdisciplinary innovation: an attractive perspective for young people as well as a must for innovative organisations.

Proceedings of the 37th Annual Conference - Attracting students in Engineering. Rotterdam, The Netherlands.

Rittel, H. W. J., \& Webber, M. M. (1973). Dilemmas in a general theory of planning. Policy Sciences, vol. 4, no. 2, pp. 155-169. doi.org/10.1007/BF01405730 
United Nations. (2015). The Sustainable Development Agenda. Retrieved from: https://www.un.org/sustainabledevelopment/development-agenda/

Wall, J. (2007). Simulation-Driven Design of Complex Mechanical and Mechatronic Systems (Doctoral dissertation, Blekinge Institute of Technology, Karlskrona, Sweden).

Retrieved from http://urn.kb.se/resolve?urn=urn:nbn:se:bth-00346 